\title{
Cognitive mapping analysis and regional identity
}

\author{
Renato Troffa $\cdot$ Marina Mura $\cdot$ Ferdinando Fornara \\ Pierluigi Caddeo
}

(C) Marta Olivetti Belardinelli and Springer-Verlag 2009

\section{Introduction}

The internal representation of the spatial models of the environment is usually defined through the term "cognitive map" (Tolman 1948; Lynch 1960). Cognitive mapping process is an internal representation of the spatial information, consisting in the acquisition, memorisation, recovering and decoding of environmental information (Downs and Stea 1977). It can be defined as a mental construction useful to understand the environment through remembering and processing the spatial information (Kitchin and Freundschuh 2000).

A cognitive map can be then considered as an internal model of the world that helps people to cope successfully with the demands coming from the surrounding environment. This internal model has been generally considered as an useful source of information for spatial behaviours (Golledge and Stimpson 1997; Golledge 1987).

People use different sources to develop their own image of the spatial environment with which they are interacting. Wide spaces, in particular, may include a lot of different places, as whole regions and states, requiring for several sources to be conceived and represented. Geographic regions, in turn, are defined as "spatial extended pieces of (near) earth surface that share some aspect of similarity across their extents" (Montello 2008, p. 305). These kinds of spaces are usually elaborated through a multiplicity of

R. Troffa $(\bowtie) \cdot$ M. Mura $\cdot$ P. Caddeo

Department of Economic and Social Research,

University of Cagliari, DRES, Cagliari, Italy

e-mail: renato.troffa@uniroma1.it

F. Fornara

Department of Psychology, University of Cagliari, Cagliari, Italy modalities, e.g. navigation, maps and descriptions (Tversky 2003). The scientific literature on cognitive maps has provided an useful instrument, i.e. the sketch map, for analysing the internalised cognitive map of the individuals. Sketch by means of map is an easy-to-use tool which is based on a graphical representation of the space. In fact, it relies on people's common ability to make spatial inferences and on shared spatial schemes, insofar it can be considered a reliable method of data collection (Blades 1990).

Usually, sketch maps are characterised by a series of biases due to perceptual cognitive factors that affects memory, so that people seem to reorganise completely the spatial information by semantic categories (McNamara et al. 1992). Nevertheless, primary aspects are not the only factors involved in the cognitive mapping process, especially in the case of regional maps. In fact, the bigger is the area represented in the map, the bigger is the role of symbolic aspects of the environment (Pinheiro 1998). In this sense, the study of mental representations of geographic regions and wide areas can provide information about the way in which people organise their world in a recognisable and manageable way (Ittelson et al. 1974). Following this conceptual line, the method of the sketch maps has met the interest of the Environmental Psychology domain, with particular reference to the depiction of broad levels of territorial scale (such as regions and nations, e.g. see Pinheiro 1998). In fact, this method is often used, in literature, to detect those psychosocial dimensions (such as social and place identity) that express the transactional pattern between people and their social-physical environment.

One of the psychological patterns that can influence people-environment transaction and, in particular, the organisation of spatial information is place identity that 
refers to those aspects of personal identity influenced by the places with which people interact (Proshansky et al. 1983; Lalli 1992). As stressed by Twigger-Ross and Uzzell (1996), places can influence the identity process according to the four principles proposed by the Breakwell's model: self-esteem, self-efficacy, distinctiveness and continuity. Coherently with this framework, places that support the identity process can easily convert themselves in places in which the individuals can identify. As noted by Lewicka (2008), different transactions with places "due either to local or national identity should have different cognitive and motivational consequences" (p. 212).

Starting from these assumptions, the purpose of the present work is to investigate the relationship between regional identification and sketch maps depicting one's own region.

In particular, it was hypothesised that the higher is the regional identification, the more detailed are the sketch maps.

\section{Method}

\section{Participants}

A total of 100 students of the University of Cagliari (Sardinia, an Italian Region), from 18 to 33 years old $(M=24, \mathrm{SD}=3.6)$, participated in the study. Participants were 66 males and 34 women, all born and residents in Sardinia.

\section{Tools and procedures}

The tools had the format of a self-administered questionnaire including the following sections.

1. A blank space where to draw the map of the region. The sketch maps were then evaluated by two independent judges, following the response scale suggested by an expert of urban planning and design (see Nenci et al. 2000) and based on map level of detail, ranging from 1 (unintelligible) to 5 (rich, complex and detailed).

2. A 10-item scale measuring the regional identification (Hernández et al. 2007). The response scale was a 7-point Likert-type. Participants rated how well each sentence was adequate to describe their relationship with the place [from 1 (not at all) to 7 (at all)].

3. A final part aiming to collect socio-demographic data.

All the participants completed the task in a controlled situation and in a fixed setting (i.e. the Lab of the Department of Psychology). It was a neutral setting with no images, photos or other possible disturbing elements. The setting was kept fixed for all the participants to control possible differences due to: geographical elements that can influence the drawing of the maps; identitarian features that can influence the answers on the scale of identification. Participants were asked to fill the three different parts of the questionnaire in the same order in which they were presented to preserve the not intrusive and not suggestive nature of the drawing map task. All the participants completed the task in about $10 \mathrm{~min}$.

\section{Data analysis}

As concerns data elaboration, a principal component analysis was run for the scale of identification, producing a mono-factorial solution. Cronbach's Alpha was calculated to test factors' internal consistency, showing a satisfactory reliability $(=0.87)$. In order to test our hypotheses, an aggregated score of identification was computed. Then, this score was used to split the sample into three nearly equal groups on the basis of the distribution, and only the two more polarised groups (i.e. the $33 \%$ of highest scores-the most identified, and the $33 \%$ of lowest scores-the least identified) were subsequently used in the following ANOVA, where level of identification was used as IV and level of detail of the sketch maps of the region as DV, controlling for gender.

\section{Results}

The outcomes of the ANOVA confirmed our design hypothesis, since it emerged a significant effect of regional identification on the map's level of detail $\left[F_{(1 ; 69)}=6.50\right.$ $(P<0.05)]$. High-identified participants drawn more complex and detailed sketch maps $(M=3.53, \mathrm{SD}=0.70)$ than the low-identified ones $(M=3.03, \mathrm{SD}=0.92)$. The covariate gender was not significant $(P=$ n.s. $)$

\section{Discussion}

This study was carried out to test the relationship between the development of an identitarian bond (as the result of identification processes) and the quality of the sketch maps. It was hypothesised that a higher level of place identification can play a role in the quality and richness of the spatial representation of the place itself. The results supported our hypothesis, confirming the effect of regional identification on the accuracy, clarity and detail of the drawn regional map. In other words, the more the people are identified with their region, the more they are able to 
recover and express detailed graphical information about their region itself.

Thus, the pattern of place identity seems to show a cognitive consequence, as stated by Lewicka (2008), and confirms its overall importance in shaping our transaction with places (Proshansky et al. 1983), even in spatial-representational terms.

Such finding needs confirmation in other contexts, both at the same level of scale (i.e. other regional areas) and both at a higher level (e.g. nation or union of nations) or a lower one (e.g. urban area) levels of scale. In particular, it is necessary to remark the particular distinctiveness of the Region of Sardinia, in terms of both spatial-geographical (it is an island) and identitarian (its residents are typically highly identified with their region) peculiarities. Anyway, the target area (i.e. the geographical region) was kept constant for all the sample, so that it can be assumed that the observed differences in the sketch maps can be attributed to identitarian factors rather than to differences in the salience of geographic elements or boundaries.

In conclusion, these results seem to stress the importance of place identification on the spatial representation of the environment, at least at a regional level. The method of the sketch maps appears as a promising tool to investigate the complex interaction among spatial, cognitive and psychosocial aspects in the multi-dimensional transaction with our surrounding environments. Thus, further studies on this topic are needed to explore the relationship between place identification and spatial representation of the environment at different levels of territorial scale.

\section{References}

Blades M (1990) The reliability of data collected from sketch maps. J Environ Psychol 10:327-339
Downs RM, Stea D (1977) Maps in minds: reflections on cognitive mapping. Harper and Row, New York

Golledge R (1987) Environmental Cognition. In: Stokols D, Altman I, Wilhelms E (eds) Handbook of environmental psychology. Wiley, New York, pp 131-174

Golledge R, Stimpson RJ (1997) Spatial Behaviour: a geographic perspective. The Guilford Press, New York

Hernández B, Hidalgo MC, Salazar-Laplace ME, Hess S (2007) Place attachment and place identity in natives and non-natives. J Environ Psychol 27:310-319

Ittelson WH, Proshanksy HM, Rivlin LG, Winkel GH (1974) An introduction to environmental psychology. Holt, Reinhart \& Winston, New York

Kitchin RM, Freundschuh S (eds) (2000) Cognitive mapping: past, present and future. Routledge, London

Lalli M (1992) Urban related identity: theory, measurement and empirical findings. J Environ Psychol 12:285-303

Lewicka M (2008) Place attachment, place identity, and place memory: restoring the forgotten city past. J Environ Psychol 28:209-231

Lynch K (1960) The image of the city. MIT Press, Cambridge

McNamara TP, Halpin J, Hardy J (1992) The representation and integration in memory of spatial and nonspatial information. Mem Cogn 20:519-532

Montello DR (2008) Geographic regions as brute facts, social facts, and institutional facts. In: Smith B, Mark DM, Ehrlich I (eds) The mystery of capital and the construction of social reality. Open Court, Chicago, pp 305-316

Nenci AM, Masala F, Mura M, Carrus G (2000). La ricerca: costruzione del luogo urbano di residenza nella rappresentazione degli abitanti di tre quartieri storici della città di Cagliari. In Nenci AM. La città immaginata. Tema, Cagliari, pp 41-127

Pinheiro J (1998) Determinants of cognitive maps of the world as expressed in sketch maps. J Environ Psychol 18:321-339

Proshansky HM, Fabian AK, Kaminoff R (1983) Place-identity: physical world socialization of the self. J Environ Psychol 3:5783

Tolman EC (1948) Cognitive maps in rats and men. Psychol Rev $55: 189-208$

Tversky B (2003) Structures of mental spaces: how people think about space. Environ Behav 35:66-80

Twigger-Ross C, Uzzell D (1996) Place and Identity process. J Environ Psychol 16:205-220 